Correspondence: Nicolas Roche, Pneumologie et Soins Intensifs Respiratoires, Groupe Hospitalier Cochin Broca HôtelDieu, Site HIA du Val de Grâce 4eC, 74 Bd de Port Royal, 75005 Paris, France. Email: nicolas.roche@cch.aphp.fr

Received: July 182014 | Accepted after revision: Aug 302014 | First published online: Oct 302014

Support statement: This study was supported by an unrestricted grant from Boehringer Ingelheim and Pfizer.

Conflict of interest: Disclosures can be found alongside the online version of this article at erj.ersjournals.com

\title{
References
}

1 Global Initiative for Chronic Obstructive Lung Disease. Global strategy for the diagnosis, management and prevention of chronic obstructive lung disease. www.goldcopd.org/uploads/users/files/GOLD_Report_2014_Jun11.pdf Date last updated: June 11, 2014.

2 Vogelmeier C, Hederer B, Glaab T, et al. Tiotropium versus salmeterol for the prevention of exacerbations of COPD. N Engl J Med 2011; 364: 1093-1103.

3 Calverley PM, Anderson JA, Celli B, et al. Salmeterol and fluticasone propionate and survival in chronic obstructive pulmonary disease. N Engl J Med 2007; 356: 775-789.

4 Karner C, Cates CJ. Combination inhaled steroid and long-acting $\beta_{2}$-agonist in addition to tiotropium versus tiotropium or combination alone for chronic obstructive pulmonary disease. Cochrane Database Syst Rev 2011; 3: CD008532.

5 Sharif R, Cuevas CR, Wang Y, et al. Guideline adherence in management of stable chronic obstructive pulmonary disease. Respir Med 2013; 107: 1046-1052.

6 Burgel PR, Deslée G, Jebrak G, et al. Real-life use of inhaled corticosteroids in COPD patients versus the GOLD proposals: a paradigm shift in GOLD 2011? Eur Respir J 2014; 43: 1201-1203.

7 Fitch K, Iwasaki K, Pyenson B, et al. Variation in adherence with Global Initiative for Chronic Obstructive Lung Disease (GOLD) drug therapy guidelines: a retrospective actuarial claims data analysis. Curr Med Res Opin 2011; 27: 1425-1429.

8 Jochmann A, Scherr A, Jochmann DC, et al. Impact of adherence to the GOLD guidelines on symptom prevalence, lung function decline and exacerbation rate in the Swiss COPD cohort. Swiss Med Wkly 2012; 142: w13567.

9 Asche CV, Leader S, Plauschinat C, et al. Adherence to current guidelines for chronic obstructive pulmonary disease (COPD) among patients treated with combination of long-acting bronchodilators or inhaled corticosteroids. Int J Chron Obstruct Pulmon Dis 2012; 7: 201-209.

10 Antón E. How and when to use inhaled corticosteroids in chronic obstructive pulmonary disease? Expert Rev Respir Med 2013; 7: 25-32.

11 De Backer W, Vos W, Van Holsbeke C, et al. The effect of roflumilast in addition to LABA/LAMA/ICS treatment in COPD patients. Eur Respir J 2014; 44: 527-529.

12 Page C, Cazzola M. Bifunctional drugs for the treatment of asthma and chronic obstructive pulmonary disease. Eur Respir J 2014; 44: 475-482.

13 Agustí A, de Teresa L, De Backer W, et al. A comparison of the efficacy and safety of once-daily fluticasone furoate/vilanterol with twice-daily fluticasone propionate/salmeterol in moderate to very severe COPD. Eur Respir J 2014; 43: 763-772.

14 Spagnolo P, Fabbri LM, Bush A. Long-term macrolide treatment for chronic respiratory disease. Eur Respir J 2013; 42: $239-251$.

\section{Volumetric and scintigraphic changes following endoscopic lung volume reduction}

To the Editor:

Bronchoscopic treatment of emphysema represents an emerging therapeutic modality for advanced emphysematous lung destruction in chronic obstructive pulmonary disease (COPD). Within the proposed techniques for endoscopic lung volume reduction (ELVR), a significant amount of experience exists for the placement of endobronchial valves (EBV) (Zephyr ${ }^{\circledast}$ valves; Pulmonx, Inc., Redwood City, CA, USA) targeting atelectasis of the treated, emphysematous lobe [1, 2]. However, post-procedural clinical 
improvement has also been documented in patients lacking lobar exclusion 3. While volumetric and density adaptations following ELVR have repeatedly been a focus [3, 4], the interaction of volume and perfusional/ventilatory changes remains unclear. In this observational study, we defined the extent of interdependency of ELVR-mediated volumetric and scintigraphic adaptations.

Among 36 patients receiving ELVR by EBV insertion at the Dept of Pneumology, University Hospital Bonn (Bonn, Germany) from November 2012 to February 2014, 24 patients were offered pre- and post-procedural imaging and qualified as eligible for inclusion in this study. As a pre-requisite for performance of ELVR, patients were required to meet the inclusion criteria of the Endobronchial Valve for Emphysema Palliation Trial (VENT) study [1]. Exclusion criteria for ELVR and consequently for study inclusion comprised continued nicotine consumption and frequent respiratory exacerbations $(\geqslant 2$ exacerbations per year). Flexible bronchoscopy was performed by an experienced bronchoscopist and executed under moderate sedation with propofol and midazolam, permitting spontaneous breathing. Absence of collateral ventilation as assessed by the Chartis ${ }^{\circledast}$ Pulmonary Assessment System (Pulmonx, Inc.) allowed for EBV placement [5]. The study had the approval of the local ethics committee.

The day prior to ELVR and 8 weeks afterwards, all patients underwent pulmonary function assessment, 6-min walk test (6MWT), COPD Assessment Test and $\mathrm{N}$-terminal pro-brain natriuretic peptide (NT-proBNP) testing. In the same time interval, ventilation/perfusion scintigraphy was conducted and complemented by single-photon emission computed tomography (SPECT)/low-dose computed tomography imaging (scan parameters: $130 \mathrm{kVm} 17 \mathrm{mAs}, 5-\mathrm{mm}$ slices). Scintigraphy and SPECT analyses were performed by experienced local nuclear physicians, blinded to the patient's clinical performance, by use of OsiriX ${ }^{\oplus}$ Medical Imaging Software (an open-source project; Pixmeo, Geneva, Switzerland).

Continuous variables were evaluated by use of paired t-test, categorical parameters by Pearson's Chi-squared test. A value of $\mathrm{p}<0.05$ was considered statistically significant. The Spearman correlation test was applied for correlation analysis of volumetric, perfusional and ventilatory changes over time.

Pre-procedural clinical data of the 24 included patients are summarised in table 1 . The study population comprised $58.3 \%$ males (14 out of 24 ) and exhibited a mean \pm SD age of $64.3 \pm 8.8$ years; all study participants were former smokers with a mean \pm SD of $39.8 \pm 14.3$ pack-years. In a majority (37.5\%) of the patients, the right upper lobe was targeted (left lower lobe $29.2 \%$, right lower lobe $20.8 \%$, left upper lobe $12.5 \%$ ); the median number of EBV inserted per patient was four. Overall, the complication rate was low. Post-procedurally, exacerbations of COPD occurred in $12.5 \%$ of patients $(n=3)$; two (8.3\%) patients developed pneumothorax, both of whom were managed successfully by temporary chest tube implantation.

Post-procedural pulmonary function testing exhibited an increase in forced expiratory volume in $1 \mathrm{~s}$ by $15.3 \%$ of predicted $(\mathrm{p}=0.06)$ (table 1 ). Contrary to mean residual volume, the mean reduction in residual volume/total lung capacity ratio reached statistical significance $(\mathrm{p}=0.04)$. On average, target lobe volume decreased by $444.6 \mathrm{~mL}$ in absolute and $36.8 \%$ in relative terms $(\mathrm{p}=0.004)$ and correlated with target lobe perfusional changes (Spearman's rho 0.56; $\mathrm{p}=0.04$ ), which in turn were linked to target lobe ventilatory adaptations (Spearman's rho 0.67; $\mathrm{p}=0.03$ ). The ipsilateral and contralateral nontargeted lobes, as well as the contralateral concordant lobe, experienced volumetric increases that were significantly associated with one another. Clinical responsiveness to ELVR assessed by $6 \mathrm{MWT}$ and defined by a post-procedural improvement in 6MWT distance $\geqslant 25 \mathrm{~m}$ [6] was exhibited by $17(70.8 \%)$ patients. Irrespective of clinical responder status, changes in $6 \mathrm{MWT}$ distance correlated significantly with development of NT-proBNP levels (Spearman's rho -0.96; $\mathrm{p}<0.001$ ). However, changes in both 6MWT and NT-proBNP were uninfluenced by the extent of volumetric and scintigraphic adaptations.

The mechanisms by which ELVR is supposed to alleviate dyspnoea in emphysematous COPD include reduction of overall hyperinflation with improvement in diaphragm mechanics and recovery of elastic retraction [7]. In the case of EBV insertion, lobar atelectasis is considered pre-requisite for treatment response. As clinical improvement also occurs in the absence of lobar exclusion [3], other mechanisms appear to have an impact on therapeutic outcome. Definition of volumetric, perfusional and ventilatory adaptations following unilateral EBV insertion and their interaction may clarify the underlying processes.

The observed mean reduction of target lobe volume accounting for $444.6 \mathrm{~mL}$ (95\% CI 186.1-703.1 mL) is consistent with HerTh et al. [8], who defined a pre- to post-treatment volume reduction of $\geqslant 350 \mathrm{~mL}$ as significant. Volume was redistributed to the ipsilateral, nontreated lung (relative volume gain 11.9\%), followed by the contralateral, nonconcordant lung (relative volume gain 11.5\%) and the contralateral, concordant lobe (relative volume gain 7.3\%). Volume redistribution occurred in mutual interdependency; however, total lung volume remained unaltered. Simultaneously, target lobe volumetric decrease was significantly associated with perfusion reduction (relative perfusional reduction $41.5 \%$ ), which in turn 
TABLE 1 Pulmonary functional, volumetric, ventilatory, perfusional and clinical changes at 8-week follow-up ${ }^{\#}$

\begin{tabular}{|c|c|c|c|}
\hline Baseline & Week 8 & Absolute change & Relative change \% \\
\hline
\end{tabular}

\begin{tabular}{|c|c|c|c|c|c|}
\hline \multicolumn{6}{|l|}{ Pulmonary function } \\
\hline FEV $1 \mathrm{~L}$ & $0.91 \pm 0.24$ & $1.03 \pm 0.33$ & $0.12(-0.11-0.25)$ & 13.2 & 0.07 \\
\hline $\mathrm{FEV}_{1} \%$ predicted & $32.99 \pm 6.39$ & $38.02 \pm 12.41$ & $5.03(-0.14-10.20)$ & 15.3 & 0.06 \\
\hline RV L & $5.71 \pm 0.97$ & $5.38 \pm 1.63$ & $-0.34(-0.99-0.32)$ & -6.0 & 0.30 \\
\hline RV \% predicted & $256.03 \pm 48.31$ & $236.99 \pm 66.35$ & $-19.04(-49.81-11.73)$ & -7.4 & 0.21 \\
\hline $\mathrm{RV} / \mathrm{TLC}$ ratio & $74.83 \pm 6.32$ & $70.87 \pm 10.11$ & $-3.96(-8.26-0.35)$ & -5.3 & 0.07 \\
\hline $\mathrm{RV} / \mathrm{TLC}$ ratio $\%$ predicted & $188.77 \pm 23.97$ & $177.42 \pm 25.79$ & $-11.35(-22.45--0.25)$ & -6.0 & 0.04 \\
\hline \multicolumn{6}{|l|}{ SPECT-guided volumetry $\mathrm{mL}$} \\
\hline Target lobe & $1207.6 \pm 390.3$ & $762.9 \pm 318.3$ & $-444.6(-703.1--186.1)$ & -36.8 & 0.004 \\
\hline Ipsilateral, nontargeted lung & $1229.9 \pm 279.6$ & $1376.0 \pm 302.8$ & $146.1(4.6-287.5)$ & 11.9 & 0.04 \\
\hline Total targeted lung & $2437.6 \pm 451.9$ & $2250.1 \pm 570.6$ & $-187.4(-375.1-0.2)$ & -7.7 & 0.05 \\
\hline Contralateral, concordant lobe & $1120.7 \pm 251.9$ & $1202.9 \pm 264.7$ & $82.2(-19.6-184.0)$ & 7.3 & 0.10 \\
\hline Contralateral, nonconcordant lung & $1437.9 \pm 451.5$ & $1602.9 \pm 611.1$ & $165.0(-68.2-398.3)$ & 11.5 & 0.14 \\
\hline Total nontargeted lung & $2558.6 \pm 578.1$ & $2694.8 \pm 586.3$ & $136.1(-91.6-363.9)$ & 5.3 & 0.21 \\
\hline \multicolumn{6}{|l|}{ Scintigraphy-guided ventilation \% } \\
\hline Target lobe & $8.38 \pm 3.98$ & $5.25 \pm 3.31$ & $-3.13(-5.25--1.00)$ & -37.4 & 0.007 \\
\hline Ipsilateral, nontargeted lung & $37.83 \pm 7.52$ & $40.26 \pm 8.44$ & $2.43(0.06-4.80)$ & 6.4 & 0.04 \\
\hline Total targeted lung & $46.31 \pm 7.18$ & $45.60 \pm 7.72$ & $-0.72(-3.51-2.08)$ & -1.6 & 0.59 \\
\hline Contralateral, concordant lobe & $14.00 \pm 5.22$ & $13.32 \pm 5.69$ & $-0.69(-3.44-2.07)$ & -4.9 & 0.60 \\
\hline Contralateral, nonconcordant lung & $39.69 \pm 4.22$ & $41.24 \pm 6.97$ & $1.56(-1.68-4.79)$ & 3.9 & 0.32 \\
\hline Total nontargeted lung & $53.69 \pm 7.18$ & $54.53 \pm 7.68$ & $0.84(-1.95-3.64)$ & 1.6 & 0.53 \\
\hline \multicolumn{6}{|l|}{ Scintigraphy-guided perfusion $\%$} \\
\hline Target lobe & $8.82 \pm 3.48$ & $5.16 \pm 2.72$ & $-3.66(-5.06--2.26)$ & -41.5 & $<0.001$ \\
\hline Ipsilateral, nontargeted lung & $35.67 \pm 7.51$ & $36.47 \pm 8.20$ & $0.80(-1.30-2.89)$ & 2.2 & 0.44 \\
\hline Total targeted lung & $44.48 \pm 8.16$ & $42.56 \pm 9.24$ & $-1.92(-4.85-1.00)$ & -4.3 & 0.19 \\
\hline Contralateral, concordant lobe & $14.72 \pm 5.75$ & $15.19 \pm 5.94$ & $0.47(-1.34-2.29)$ & 3.2 & 0.59 \\
\hline Contralateral, nonconcordant lung & $40.81 \pm 7.19$ & $43.08 \pm 8.32$ & $2.27(0.45-4.09)$ & 5.6 & 0.02 \\
\hline Total nontargeted lung & $55.50 \pm 8.16$ & $58.35 \pm 8.39$ & $2.85(0.44-5.26)$ & 5.1 & 0.02 \\
\hline \multicolumn{6}{|l|}{ Patient outcomes } \\
\hline 6MWT m & $298.6 \pm 120.4$ & $365.9 \pm 119.9$ & $67.4(17.1-117.6)$ & 22.6 & 0.01 \\
\hline NT-proBNP pg.mL ${ }^{-1}$ & $175.6 \pm 126.4$ & $153.6 \pm 139.4$ & $-22.0(-162.9-118.9)$ & -12.5 & 0.72 \\
\hline CAT points & $24.8 \pm 7.3$ & $22.6 \pm 6.2$ & $-2.2(-5.7-1.4)$ & -8.9 & 0.21 \\
\hline
\end{tabular}

Data are presented as mean $\pm \mathrm{SD}$, unless otherwise stated. FEV1: forced expiratory volume in $1 \mathrm{~s}$; RV: residual volume; TLC: total lung capacity; SPECT: single-photon emission computed tomography; 6MWT: 6-min walk test; NT-proBNP: N-terminal pro-brain natriuretic peptide; CAT: Chronic obstructive pulmonary disease Assessment Test. ${ }^{\#}: \mathrm{n}=24$.

correlated with ventilatory shifts. Both perfusion and ventilation were primarily redistributed to the contralateral nonconcordant and ipsilateral nontreated lobes. This gives evidence to show in which direction air and blood flow shifts post-ELVR and offers the possibility to optimise ELVR outcome by pre-procedural evaluation of its functional reserves.

Atelectasis occurred in $15(62.5 \%)$ patients (including both aforementioned patients offering pneumothorax) and led to a mean target lobe volume reduction of $549.0 \mathrm{~mL}$ (95\% CI 63.6-1034.5 mL; $\mathrm{p}=0.035$ ), but was not significantly associated with clinical responsiveness, defined by improvement in 6MWT [6]. In turn, clinical responder status was accompanied by reduction of NT-proBNP levels. Although exercise limitation in emphysematous COPD has multiple contributory factors, the currently observed significant, post-procedural gain in exertional capacity has previously been shown to correlate with an improved left ventricular diastolic filling pattern, which in turn is associated with reduced dynamic hyperinflation [9]. Attenuation of progressive hyperinflation during exercise might partially restore cardiocirculatory function and consequently contribute to tapering NT-proBNP levels.

The finding that gain in 6MWT distance occurred irrespective of the extent of volumetric and scintigraphic shifts may be ascribed to the quality in terms of pulmonary capacity of the lobes to which ventilation and perfusion is directed, rather than to the mere quantity of shifted air and blood flows. This result is in line with CHUNG et al. [10], who performed serial scintigraphic assessment in six patients undergoing ELVR exclusively of the left upper lobe and determined a redistribution of ventilation and perfusion to the right lower region. In the current study, we additionally evaluated volumetric data and 
found that redistribution was not solely directed to pulmonary regions but to concrete anatomic lobes. Moreover, we achieved a generalised redistribution pattern, irrespective of the treated lobe.

Consistent with Coxson et al. [3], we found total lung volume to remain unchanged but described interlobar volumetric shifts. Although Coxson et al. [3] only suggested perfusional and ventilatory changes underlying the physiological response to ELVR, we merged volumetric and scintigraphic data for the first time and identified significant mutual interdependency.

In summary, ELVR by EBV insertion is accompanied by volumetric and scintigraphic adaptations and favours exertional performance. Pre-procedural evaluation of contralateral lung emphysematous destruction and functional capability may be a valuable tool to predict ELVR efficacy.

0 @ERSpublications

EBV treatment reduces target lobe volume, ventilation and perfusion with consistent redistributive pattern http://ow.ly/C95Ue

Carmen Pizarro $^{1}$, Hojjat Ahmadzadehfar ${ }^{2}$, Markus Essler ${ }^{2}$, Rolf Fimmers ${ }^{3}$, Georg Nickenig ${ }^{1}$ and Dirk Skowasch ${ }^{1}$

${ }^{1}$ Dept of Internal Medicine II, Cardiology, Pneumology and Angiology, University Hospital Bonn, Bonn, Germany. ${ }^{2}$ Dept of Nuclear Medicine, University Hospital Bonn, Bonn, Germany. ${ }^{3}$ Institute for Medical Biometry, Informatics and Epidemiology, University Hospital Bonn, Bonn, Germany.

Correspondence: Carmen Pizarro, Dept of Internal Medicine II, Cardiology, Pneumology and Angiology, University Hospital Bonn, Sigmund-Freud-Straße 25, 53105 Bonn, Germany. E-mail: carmen.pizarro@ukb.uni-bonn.de

Received: June 152014 | Accepted after revision: Sept 212014 | First published online: Oct 302014

Support statement: This study has been funded by Pulmonx, Inc., Redwood City, CA, USA. None of the authors had any ownership interest in the company.

Conflict of interest: Disclosures can be found alongside the online version of this article at erj.ersjournals.com

\section{References}

1 Sciurba FC, Ernst A, Herth FJ, et al. A randomized study of endobronchial valves for advanced emphysema. $N$ Engl J Med 2010; 363: 1233-1244.

2 Herth FJ, Noppen M, Valipour A, et al. Efficacy predictors of lung volume reduction with Zephyr valves in a European cohort. Eur Respir J 2012; 39: 1334-1342.

3 Coxson HO, Nasute Fauerbach PV, Storness-Bliss C, et al. Computed tomography assessment of lung volume changes after bronchial valve treatment. Eur Respir J 2008; 32: 1443-1450.

4 Brown MS, Kim HJ, Abtin FG, et al. Emphysema lung lobe volume reduction: effects on the ipsilateral and contralateral lobes. Eur Radiol 2012; 22: 1547-1555.

5 Mantri S, Macaraeg C, Shetty S, et al. Technical advances: measurement of collateral flow in the lung with a dedicated endobronchial catheter system. J Bronchology Interv Pulmonol 2009; 16: 141-144.

6 Holland AE, Hill CJ, Rasekaba T, et al. Updating the minimal important difference for six-minute walk distance in patients with chronic obstructive pulmonary disease. Arch Phys Med Rehabil 2010; 91: 221-225.

7 O'Donnell DE, Webb KA. The major limitation to exercise performance in COPD is dynamic hyperinflation. $J$ Appl Physiol 2008; 105: 753-755.

8 Herth FJ, Eberhardt R, Gompelmann D, et al. Radiological and clinical outcomes of using Chartis ${ }^{\mathrm{TM}}$ to plan endobronchial valve treatment. Eur Respir J 2013; 41: 302-308.

9 Watz H, Waschki B, Meyer T, et al. Decreasing cardiac chamber sizes and associated heart dysfunction in COPD: role of hyperinflation. Chest 2010; 138: 32-38.

10 Chung SC, Peters MJ, Chen S, et al. Effect of unilateral endobronchial valve insertion on pulmonary ventilation and perfusion: a pilot study. Respirology 2010; 15: 1079-1083. 